\title{
Carbohydrate and protein intake during exertional-heat stress ameliorates intestinal epithelial injury and small intestine permeability.
}

\author{
Rhiannon M.J. Snipe ${ }^{1}$, Anthony Khoo ${ }^{1}$, Cecilia M. Kitic ${ }^{2}$, Peter R. Gibson ${ }^{3}$, Ricardo J.S. Costa ${ }^{1}$. \\ ${ }^{1}$ Monash University, Department of Nutrition, Dietetics and Food, Level 1, 264 Ferntree Gully \\ Road, Notting Hill, Victoria 3168, Australia; ${ }^{2}$ University of Tasmania, Sport Performance \\ Optimisation Research Team, School of Health Sciences, Locked Bag 1322, Launceston, Tasmania \\ 7250, Australia; ${ }^{3}$ Monash University, Department of Gastroenterology- The Alfred Hospital, 55 \\ Commercial Road, Melbourne, 3004 Victoria, Australia.
}

\section{Corresponding author:}

Ricardo J.S. Costa: Monash University, Department of Nutrition, Dietetics and Food, Level 1, 264 Ferntree Gully Road, Notting Hill, 3168, Victoria, Australia. Telephone: 00613 99024270. Email: ricardo.costa@monash.edu

Rhiannon Snipe (rhiannon.snipe@monash.edu), Anthony Khoo (aykho3@student.monash.edu), Cecilia Kitic (Cecilia.kitic@utas.edu.au), Peter Gibson (peter.gibson@monash.edu). 


\section{ABSTRACT}

Background: Exertional-heat stress (EHS) disturbs the integrity of the gastrointestinal tract leading to endotoxaemia and cytokinaemia, which have symptomatic and health implications. This study aimed to determine the effects of carbohydrate and protein intake during EHS on gastrointestinal integrity, symptoms and systemic responses. Methods: Eleven (male $n=6$, female $n=5$ ) endurance runners completed $2 \mathrm{~h}$ running at $60 \% \dot{\mathrm{VO}}_{2 \max }$ in $35^{\circ} \mathrm{C}$ ambient temperature on three occasions in randomised order, consuming water (WATER) or 15g glucose (GLUC) or energy-matched whey protein hydrolysate (WPH) before and every 20min during EHS. Rectal temperature and gastrointestinal symptoms were recorded every 10min during EHS. Blood was collected pre- and post-EHS, and during recovery to determine plasma concentrations of intestinal fatty-acid binding protein (I-FABP) as a marker of intestinal epithelial injury, cortisol, endotoxin, and inflammatory cytokines. Urinary lactulose:L-rhamnose was used to measure small intestine permeability. Results: Compared to WATER, GLUC and WPH ameliorated EHS-associated intestinal epithelial injury (IFABP: $897 \pm 478 \mathrm{pg} \cdot \mathrm{ml}^{-1}$ vs. $123 \pm 197 \mathrm{pg} \cdot \mathrm{ml}^{-1}$ and $82 \pm 156 \mathrm{pg} \cdot \mathrm{ml}^{-1}$, respectively, $\left.p<0.001\right)$ and small intestine permeability (lactulose:L-rhamnose ratio $0.034 \pm 0.014$ vs. $0.017 \pm 0.005$ and $0.008 \pm 0.002$, respectively, $p=0.001)$. Endotoxaemia was observed post-EHS in all trials $\left(10.2 \mathrm{pg} \cdot \mathrm{ml}^{-1}, p=0.001\right)$. Post-EHS anti-endotoxin antibodies were higher $(p<0.01)$ and cortisol and IL-6 lower $(p<0.05)$ on GLUC than WATER only. Total and upper-gastrointestinal symptoms were greater on WPH, compared to GLUC and WATER $(p<0.05)$, in response to EHS. Conclusion: Carbohydrate and protein intake during EHS ameliorates intestinal injury and permeability. Carbohydrate also supports endotoxin clearance and reduces stress markers, while protein appears to increase gastrointestinal symptoms. Suggesting carbohydrate is a more appropriate option.

Keywords: Heat exposure, running, glucose, whey protein hydrolysate, I-FABP, gastrointestinal symptoms. 


\section{Introduction}

Exposure to hot ambient temperatures is common in many sports and exertional activities. Exertional heat stress (EHS) exacerbates splanchnic hypoperfusion, hyperthermic injury and perturbations of intestinal barrier function that may lead to endotoxaemia and subsequent systemic inflammatory responses (i.e., cytokinaemia), and the development of gastrointestinal symptoms (Costa et al. 2017a). These gastrointestinal disturbances and systemic responses have been linked to several acute and chronic health conditions, including fatal septic shock, ischaemic colitis, paralytic ileus, inflammatory bowel disease and chronic fatigue syndrome (Caradonna et al. 2000; Cohen et al. 2009; Morris et al. 2014; Rav-Acha et al. 2004; Sanchez et al. 2006). Indeed, endotoxaemia, cytokinaemia, and gastrointestinal symptoms have been consistently observed during and after endurance events with exposure to hot ambient conditions (Costa et al. 2016; Gill et al. 2015b; Jeukendrup et al. 2000; Stuempfle and Hoffman 2015; Stuempfle et al. 2013). Gastrointestinal symptoms during these events consistently affect $\geq 60 \%$ of athletes, making them a major medical issue that can compromise exercise performance, nutrient intake during and after exercise, and, in severe cases, cause withdrawal from competition (Costa et al. 2017a).

Considering postprandial hyperaemia increases splanchnic perfusion and microvascular blood flow in intestinal villi, it is plausible that repeated macronutrient intake during EHS may ameliorate gastrointestinal perturbations by improving splanchnic perfusion (Matheson et al. 2000; Qamar and Read 1987; van Wiijck et al. 2012). Furthermore, absorption of glucose and certain amino acids and (or) amino acid precursors (i.e., glutamine, aspartate, glycine, L-arginine and Lcitrulline) have been shown to produce localised metabolic vasodilators, principally nitric oxide, which may also improve intestinal microvillous perfusion during exercise (Matheson et al. 2000; van Wijck et al. 2012). Indeed, a $10 \mathrm{~g}$ bolus of L-citrulline, an L-arginine pre-cursor, before $1 \mathrm{~h}$ cycling at $70 \%$ maximal workload $\left(\mathrm{W}_{\max }\right)$ improved splanchnic perfusion and reduced circulating levels of intestinal fatty-acid binding protein (I-FABP), a sensitive marker of intestinal epithelial injury and damage, during exercise (Grootjans et al. 2016; van Wijck et al. 2014). 
In addition to postprandial hyperaemia, it has been proposed that certain amino acids, for example glutamine, may enhance the expression of heat shock proteins which can prevent injury to the intestinal epithelium; and subsequently reduce intestinal permeability, and localised and systemic inflammatory responses (Dokladny et al. 2006; Zuhl et al. 2014b). Despite some promising effects on gastrointestinal integrity, the practical utility of amino acid and (or) protein intake during prolonged exercise may be somewhat limited due to reports of gastrointestinal symptoms (Grimble 2007; Rehrer et al. 1992). However, to date no studies have investigated the effects of hydrolysed whey protein, which contains a variety of amino acids and peptides in a more rapidly digested form (Koopman et al. 2009), on gastrointestinal integrity and symptoms, and systemic profiles in response to EHS.

Carbohydrate is more commonly consumed than protein during endurance exercise and has been shown to improve physical performance (Stellingwerff \& Cox 2014). However, recommended intakes of $90 \mathrm{~g} \cdot \mathrm{h}^{-1}$ multiple transportable carbohydrates during prolonged exercise (i.e., $\geq 3 \mathrm{~h}$ ) has been associated with the development of gastrointestinal symptoms, due to the inability to tolerate such high carbohydrate intakes (Costa et al. 2017b). Moreover, few studies have investigated the effects of carbohydrate intake before or during exercise on gastrointestinal integrity. Observations by Rehrer et al. (2005) reported that consumption of a glucose solution pre-exercise and every 20 min during 60 min cycling at $70 \% \dot{\mathrm{VO}}_{2 \max }$ tended to maintain portal vein blood flow to a greater extent than water, highlighting the efficacy of glucose in stimulating postprandial hyperaemia. However, other studies have observed no benefit to gastroduodenal permeability, except when aspirin was ingested pre-exercise (Lambert et al. 2001); and it appears that small infrequent carbohydrate intakes during 60-90 min steady state exercise has minimal impact on intestinal integrity (Sessions et al 2016; van Nieuwenhoven et al. 2000). Consumption of an energy gel during 60 min running at $70 \% \mathrm{VO}_{2 \max }$ has been suggested as being harmful to gastrointestinal integrity (Sessions et al. 2016). However, the small transient post-exercise increase in I-FABP $\left(\sim 263 \mathrm{pg} \cdot \mathrm{ml}^{-}\right.$ ${ }^{1}$ ) and circulatory endotoxin $\left(\sim 5 \mathrm{pg} \cdot \mathrm{ml}^{-1}\right)$ (Sessions et al. 2016) are well below the $1230 \mathrm{pg} \cdot \mathrm{ml}^{-1}$ and 
$10 \mathrm{pg} \cdot \mathrm{ml}^{-1}$ increase that we previously observed after $2 \mathrm{~h}$ running at $60 \% \mathrm{~V}_{2 \max }$ in $35^{\circ} \mathrm{C}_{\text {amb }}$ with water (Snipe et al. 2016). In addition to macronutrient intake, inadequate, excessive, and (or) prescribed fluid intakes above tolerance levels during exercise have been shown to contribute to the development of gastrointestinal symptoms, with restricted fluid intake also increasing small intestine permeability (Costa et al. 2017a; Lambert et al. 2008a; Lambert et al. 2008b). It is evident that there is currently a clear gap in the research regarding the most appropriate nutrient intake to recommend for maintenance of gastrointestinal integrity and ameliorating the associated systemic responses associated with EHS.

The current study, therefore, aimed to determine the effects of carbohydrate and protein intake before and during EHS on gastrointestinal integrity (i.e., using I-FABP as a marker of intestinal epithelial injury and lactulose:L-rhamnose ratio as a measure of small intestine permeability), systemic responses (i.e., circulatory endotoxin and inflammatory cytokine profiles) and gastrointestinal symptoms compared to ad libitum water intake. It was hypothesised that carbohydrate and protein intake would ameliorate perturbations to gastrointestinal integrity and systemic responses compared to water, but that protein intake would increase the incidence and severity of gastrointestinal symptoms compared to those associated with carbohydrate and water ingestion. 


\section{Methods}

\section{Participants}

Eleven non-heat acclimatised endurance-trained runners [mean \pm SD: (male $n=6$, female $n=$ 5) age $31 \pm 5$ years, nude body mass $65.7 \pm 12.0 \mathrm{~kg}$, height $1.72 \pm 0.09 \mathrm{~m}, \%$ body fat mass $17 \pm$ $\left.6 \%, \dot{\mathrm{VO}}{ }_{2 \max } 54 \pm 6 \mathrm{ml} \cdot \mathrm{kg} \cdot \mathrm{min}^{-1}\right]$ volunteered to participate in the study. All participants gave written informed consent. The study protocol received approval from the local ethics committee and conformed to the 2008 Helsinki Declaration for Human Research Ethics. Participants were excluded if they confirmed having gastrointestinal infections, diseases and/or disorders, consumed potential modifiers of gastrointestinal integrity (such as prebiotics, probiotics, and/or antibiotics), were adhering to gastrointestinal-focused dietary regimes (such as fibre-modified or gluten-free diets) within the previous three months, or consumed non-steroidal anti-inflammatory medications and/or stool altering medications such as laxatives and anti-diarrhoeal medication within one month before the experimental protocol.

\section{Preliminary measures}

One week before the first experimental trial, height and nude body mass (Seca 515 MBCA, Seca Group, Hamburg, Germany) were recorded. Maximal oxygen uptake $\left(\dot{\mathrm{V}}_{2 \max }\right.$; Vmax Encore Metabolic Cart, Carefusion, San Diego, California, US) was estimated by means of a continuous incremental exercise test to volitional exhaustion on a motorized treadmill (Forma Run 500, Technogym, Seattle, Washington, US), as previously reported (Costa et al. 2009). To determine running speed for the exercise trials, the speed at approximately $60 \% \mathrm{VO}_{2 \max }$ and $1 \%$ gradient was determined and verified from the $\dot{\mathrm{V}} \mathrm{O}_{2}$-work rate relationship $\left(10.3 \pm 0.7 \mathrm{~km} \cdot \mathrm{hr}^{-1}\right)$.

\section{Experimental procedure}

Participants were provided with an individualised diet low in fermentable carbohydrates (i.e., FODMAPs) for the $24 \mathrm{~h}$ period before each experimental trial $(12.4 \pm 1.8 \mathrm{MJ}, 454 \pm 69 \mathrm{~g}$ 
carbohydrate, $113 \pm 10 \mathrm{~g}$ protein, $71 \pm 13 \mathrm{~g}$ fat) to reduce gastrointestinal symptoms arising from pre-exercise food and fluid intake (Lis et al. 2016). Participants were asked to refrain from consuming additional high FODMAP foods, alcohol, and caffeinated beverages during the diet controlled period, and refrain from strenuous exercise during the $48 \mathrm{~h}$ period before each experimental trial. Compliance was determined by a dietary and exercise log. Participants reported to the laboratory at $8: 00 \mathrm{~h}$ after consuming the standardised low FODMAP breakfast $(2.5 \mathrm{MJ}, 125 \mathrm{~g}$ carbohydrate, $14 \mathrm{~g}$ protein, and $4 \mathrm{~g}$ fat) with $400 \mathrm{ml}$ of water (consumed at 07:00h). Participants were asked to void before nude body mass measurements and completion of a self-reported gastrointestinal symptom assessment tool. A 10-point Likert-type rating scale was used to quantify self-perceived gastrointestinal symptoms (adapted from a $10 \mathrm{~cm}$ visual analogue scale (Bengtsson et al. 2013; Tuck et al. 2017), with 0 indicative of no symptoms to 10 indicative of extreme symptoms, as previously reported (Costa et al. 2016; Costa et al. 2017b). Blood was then collected by venepuncture from an antecubital vein into a vacutainer $\left(6 \mathrm{ml}, 1.5 \mathrm{IU} \cdot \mathrm{ml}^{-1}\right.$ heparin). To monitor rectal temperature $\left(\mathrm{T}_{\mathrm{re}}\right)$ during running, participants inserted a thermocouple $12 \mathrm{~cm}$ beyond the external anal sphincter (Grant REC soft insertion probe thermocouple; Grant 2010 Squirrel data logger, Shepreth, UK).

In a randomised order, participants completed three experimental trials separated by oneweek, consisting of $2 \mathrm{~h}$ (initiated at 09:00h) running exercise on a motorised treadmill at the previously determined speed that elicited $60 \% \dot{\mathrm{V}} \mathrm{O}_{2 \max }$ within an environmental chamber at $35.5 \pm$ $1.4^{\circ} \mathrm{C} \mathrm{T}_{\mathrm{amb}}$ and $27 \pm 5 \%$ relative humidity. Participants were provided with an in-house formulated non-commercial energy-matched glucose (GLUC: $255 \mathrm{kj}$ of which protein $0 \mathrm{~g}$, carbohydrate $15.0 \mathrm{~g}$ and fat $0 \mathrm{~g}, 6.0 \% w / v$; Glucodin, Valeant, Laval, Quebec, Canada) or whey protein hydrolysate (WPH: 255kj of which protein $14.8 \mathrm{~g}$, carbohydrate $0.1 \mathrm{~g}$ and fat $0.1 \mathrm{~g}, 6.4 \% \mathrm{w} / \mathrm{v}$; Tatua HWP406, Morrinsville, New Zealand) solution immediately pre-exercise and every 20 min during running with additional water ad libitum, or water (WATER) ad libitum and requested to drink to maintain euhydration. In the absence of repeated gut-training with a set fluid volume, an ad libitum water 
intake regime was employed to provide autonomy over drinking patterns to minimise occurrence of gastrointestinal symptoms (Costa et al. 2017b; Lambert et al. 2008a). Participants were not advised of the contents of the GLUC and WPH solutions; however, the test solutions were not blinded due to an inability to mask the flavour of the WPH solution. Heart rate, rating of perceived exertion (RPE; 20-point Likert-type perceived exertion rating scale, with 7 indicative of very very light and 19 indicative of very very hard) (Borg 1982), thermal comfort rating (13-point Likert-type thermal rating, with 7 indicative of comfortable, 10 indicative of hot, and 13 indicative of unbearably hot) (adapted from Hollies and Goldman 1977), $\mathrm{T}_{\mathrm{re}}$, and gastrointestinal symptoms were measured every 10 min during running. To determine small intestine permeability, participants were asked to consume a dual-sugars solution containing $5 \mathrm{~g}$ lactulose (Duphalac, Abbott Biologicals, Olst, Netherlands) and $1 \mathrm{~g}$ L-rhamnose (MP Biomedicals, LLC, Solon, USA) in $100 \mathrm{ml}$ water, $90 \mathrm{~min}$ into exercise. A $5 \mathrm{~h}$ urine collection period commenced post-ingestion, where the final volume was weighed, and $30 \mathrm{ml}$ aliquoted and stored frozen at $-20^{\circ} \mathrm{C}$ until analysis. Immediately after EHS, a blood sample was collected and nude body mass was recorded. Participants remained seated during the recovery period and were provided with water ad libitum. Blood was also collected $1 \mathrm{~h}, 2 \mathrm{~h}$, and $4 \mathrm{~h}$ post-EHS. To reduce any seasonal heat acclimatisation, the experimental procedures were conducted over the cooler seasonal periods (temperatures were consistently $\leq 20^{\circ} \mathrm{C}$ ) (Costa et al. 2014).

\section{Sample analysis}

Whole blood haemoglobin and haematocrit values were used to estimate changes in plasma volume relative to baseline, and used to correct plasma variables. Blood glucose concentration was determined pre- and post-EHS using a handheld glucose monitor (Accu-Chek Proforma, Roche Diagnostics, Indianapolis, Indiana, USA). The remaining blood samples were centrifuged at 4000 rpm for 10 min within 15 min of sample collection. Plasma was aliquoted into eppendorfs and frozen at $-80^{\circ} \mathrm{C}$ until analysis, except for $50 \mu$ that was used to determine plasma osmolality 
$\left(\mathrm{P}_{\text {Osmol }}\right)$, in duplicate (coefficient of variation $\left.(\mathrm{CV}): 2.7 \%\right)$, by freezepoint osmometry (Osmomat 030, Gonotec, Berlin, Germany). Recovery of lactulose and L-rhamnose in urine was determined by ultra-performance liquid chromatography in duplicate (CV: 13.8\%). Plasma concentrations of interleukin (IL)-6, IL-1 $\beta$, tumour necrosis factor (TNF)- $\alpha$, IL-8, IL-10, and IL-1 receptor antagonist (ra) were determined by multiplex enzyme-linked immunosorbent assay (ELISA; HCYTOMAG60K, EMD Millipore, Darmstadt, Germany). Circulating gram-negative bacterial endotoxin concentration was determined by limulus amebocyte lysate (LAL) chromogenic endpoint assay (HIT302, Hycult Biotech, Uden, Netherlands). Plasma concentrations of I-FABP (HK406, Hycult Biotech, Uden, Netherlands), endotoxin core antibody (HK504, Hycult Biotech, Uden, Netherlands) and cortisol (RE52061, IBL International, Hamburg, Germany) were determined by ELISA. All variables were analysed in duplicate as per manufacturer's instructions on the same day, with standards and controls on each plate, and each participant assayed on the same plate. The CVs for cytokine profile, endotoxin, I-FABP, endotoxin core antibody, and cortisol were $2.5 \%, 3.2 \%, 5.4 \%$, $6.0 \%$, and $3.1 \%$, respectively.

\section{Statistical analysis}

Based on the typical standard deviation of $0.7 \mathrm{EU} \cdot \mathrm{ml}^{-1}$ for circulatory endotoxin responses to exertional-stress (Gill et al. 2015a; Gill et al. 2015b), and using standard alpha (0.05) and beta values (0.8) (www.dssresearch.com), a sample size of $n=8$ is estimated to provide adequate statistical precision to detect a $>10 \%$ difference in circulatory endotoxin concentration in response to EHS in the target population. Such increases in circulatory endotoxin concentration have consistently been associated with systemic inflammatory responses (Gill et al. 2015a; Gill et al. 2015b; Gill et al. 2016). Data in the text and tables are presented as mean and $95 \%$ confidence interval (CI), and accumulative score and individual participant range for gastrointestinal symptoms. For clarity, data in figures are presented as the magnitude of change with mean \pm standard error of the mean (SEM). Due to commonly reported individual variations in plasma 
cytokine responses to exercise (Gill et al. 2015a, Gill et al. 2015b; Gill et al. 2016), figures for cytokine profile has been presented as individual responses, with the removal of outliers for clarity. Only raw data and participants with full data sets within each specific variable were used in the data analysis. All data were checked for normal distribution by calculating skewness and kurtosis coefficients. Where data violated the assumption of normality (positive skewness and kurtosis), data were log-transformed prior to analysis. Variables with singular data points were examined using a one-way ANOVA; while variables with multiple data points were examined using a two-way repeated-measures ANOVA, except for gastrointestinal symptoms that were examined using Friedman's test. Assumptions of homogeneity and sphericity were checked, and when appropriate adjustments to the degrees of freedom were made using the Greenhouse-Geisser correction method. Significant main effects were analysed using a post hoc Tukey's HSD test or Wilcoxon signed rank test for gastrointestinal symptoms. Data was also analysed for order effect using a two-way repeated measures ANOVA, with no significant trial order effect observed. Statistics were analysed using SPSS statistical software (V.23.0, Chicago, Illinois, USA) with significance accepted at $\mathrm{p} \leq 0.05$. 


\section{Results}

Hydration status, cardiovascular and thermoregulatory strain

Water intake was higher $(p=0.005)$ and EHS-induced loss of body mass was lower $(p<$ 0.001) on GLUC and WPH compared to WATER (Table 1). Plasma osmolality did not differ preto post-EHS within or between trials $(p=0.393)$, indicating maintenance of euhydration. A main effect of time was observed for $\mathrm{T}_{\mathrm{re}}(p<0.001)$, which was significantly elevated from 20 min EHS onwards, compared to $10 \mathrm{~min}\left(p<0.01\right.$; Figure 1A). Peak $\mathrm{T}_{\mathrm{re}}\left(\mathrm{GLUC}\right.$ : 38.9 (38.5-39.4) ${ }^{\circ} \mathrm{C}$, WPH: $39.0(38.5-39.4)^{\circ} \mathrm{C}$ and WATER: $\left.39.3(38.8-39.8)^{\circ} \mathrm{C}\right)$ and change in $\mathrm{T}_{\mathrm{re}}$ from pre-EHS (GLUC: 2.0 (1.6-2.4 $)^{\circ} \mathrm{C}$, WPH: $2.1(1.6-2.5)^{\circ} \mathrm{C}$, and WATER: $\left.2.2(1.7-2.7)^{\circ} \mathrm{C}\right)$ were similar across all trials $(p=$ 0.103 and $p=0.175$, respectively). A main effect of time was found for heart rate $(p<0.001$; Figure 1B), rating of perceived exertion ( $p<0.001$; Figure 1C), and thermal comfort rating $(p<0.001$; Figure 1D), which were significantly elevated in all trials from 40 min EHS onwards, compared to $10 \mathrm{~min}$.

[Insert Table 1 near here]

[Insert Figure 1 near here]

\section{Plasma cortisol and blood glucose concentration}

A trial $\mathrm{x}$ time interaction was observed for plasma cortisol $(p=0.003)$ and blood glucose concentrations ( $p=0.014$; Figure 2). Plasma cortisol concentration increased pre- to post-EHS on all trials and was significantly lower immediately, $1 \mathrm{~h}$ and $2 \mathrm{~h}$ post-EHS on GLUC $(p<0.01)$, and at 1 h post-EHS on WPH $(p<0.05)$ compared to WATER. Blood glucose concentration increased preto post-EHS on all trials and was higher on GLUC compared with WPH and WATER $(p<0.01)$.

[Insert Figure 2 near here] 


\section{Gastrointestinal integrity and symptoms}

A trial $\mathrm{x}$ time interaction was found for plasma I-FABP concentrations $(p<0.001$; Figure 3$)$, those being significantly elevated immediately, $1 \mathrm{~h}$ and $2 \mathrm{~h}$ post-EHS, compared with pre-EHS values on WATER $(288 \%, 236 \%$ and $97 \%$, respectively, $p<0.01)$. However, they did not change on GLUC and WPH. Compared to WATER, I-FABP levels were significantly lower immediately, $1 \mathrm{~h}$ and $2 \mathrm{~h}$ post-EHS on GLUC and WPH $(p<0.01)$. A significantly lower lactulose:L-rhamnose ratio was observed on GLUC (0.017 (0.013-0.021)) and WPH $(0.008(0.004-0.011))$ compared to WATER (0.034 (0.022-0.046); $p=0.001)$ (Figure 4). Gut discomfort was significantly higher on WPH compared to WATER $(p=0.003)$, while total and upper-gastrointestinal symptoms were significantly higher $(p<0.01)$ on WPH and appetite significantly lower $(p<0.05)$ compared with GLUC and WATER (Table 2).

[Insert Figure 3 near here]

[Insert Figure 4 near here]

[Insert Table 2 near here]

\section{Circulating endotoxin profile}

A main effect of time was observed for plasma bacterial endotoxin concentration, which increased by a mean of $10.2 \mathrm{pg} \cdot \mathrm{ml}^{-1}(p=0.001)$, peaking immediately post-EHS (Figure 5A). A trial $\mathrm{x}$ time interaction was observed for plasma anti-endotoxin antibody concentration $(p=0.012)$ which increased post-EHS on GLUC $(23 \%, p<0.01)$ and WPH $(9 \%, p>0.05)$, and decreased on WATER $(12 \%, p>0.05)$ (Figure 5B). Post-EHS anti-endotoxin antibodies were significantly higher on GLUC compared to WATER only $(p<0.01)$.

[Insert Figure 5 near here] 
Cytokine profile

A trial $\mathrm{x}$ time interaction was observed for plasma IL-6 concentration ( $p=0.048$; Figure $6 \mathrm{~A})$, whereas, a main effect of time was observed for plasma IL-8 $(p=0.004)$, IL-10 ( $p=0.003)$ and IL1ra $(p=0.002)$ concentrations (Figure 6). Plasma IL-6 concentration significantly increased pre- to post-EHS on WATER only, and was greater than GLUC, but not WPH. Pre- to post-EHS increases in the plasma concentrations of IL-8 (85\%, peaking post-exercise), IL-10 (926\%, peaking $1 \mathrm{~h}$ postexercise) and IL-1ra (78\%, peaking 2 h post-exercise) were observed ( $p<0.05)$, with no difference between trials. A compensatory anti-inflammatory response was observed after EHS on WATER, GLUC, and WPH as evident by a significant reduction in TNF- $\alpha$ :IL-10 ratio (main effect of time; $p<0.001)$. However, this reduction was not significant for IL-1 $\beta$ :IL-10 ratio.

[Insert Figure 6 near here] 


\section{Discussion}

The current study aimed to determine the effects of carbohydrate and protein intake before and during EHS on gastrointestinal integrity, systemic responses, and gastrointestinal symptoms, compared to those with ad libitum water intake. The novel findings of the current study are that frequent ingestion of GLUC before and during EHS ameliorates intestinal epithelial injury and small intestine permeability, and enhances anti-endotoxin antibody responses compared to WATER. Further, energy-matched WPH also ameliorates intestinal epithelial injury and small intestine permeability compared to WATER. However, WPH increases the incidence and severity of gastrointestinal symptoms compared to GLUC and WATER. These findings indicate that, while frequent carbohydrate and protein ingestion both support gastrointestinal integrity during EHS, carbohydrate may be a more suitable recommendation for four reasons: 1) it was not associated with the triggering and heightened severity of gastrointestinal symptoms as observed with whey protein hydrolysate intake; 2) it supports endotoxin clearance, and results in reduced cortisol and IL-6 responses; 3) it contributes to blood glucose maintenance; and 4) it provides a rapid exogenous energy source to support skeletal muscle workload, all of which may contribute to improvements in exercise performance (Cota et al. 2017a; Stellingwerff and Cox 2014).

\section{Intestinal epithelial injury}

A novel finding was the substantial reduction in intestinal epithelial injury observed after running in $35^{\circ} \mathrm{C} \mathrm{T}_{\mathrm{amb}}$ on GLUC and WPH compared to WATER. Additionally, we observed no significant pre- to post-EHS increase in I-FABP on GLUC and WPH, indicating frequent feeding of macronutrients abolishes exercise-associated intestinal epithelial injury. Considering that 1) repeated ingestion of a glucose solution maintains portal vein blood flow during exercise (Rehrer et al. 2005); 2) I-FABP levels correlate well with splanchnic perfusion (van Wijck et al. 2011); and 3) no differences in I-FABP were found between GLUC and WPH, it is likely repeated macronutrient feeding ameliorates intestinal injury by maintaining microvascular hyperaemia in the intestine villi. 
Indeed, a reduced splanchnic hypoperfusion during exercise has been observed after ingestion of $10 \mathrm{~g}$ of L-citrulline compared with $20 \mathrm{~g}$ L-alanine (placebo), providing further evidence on the beneficial effects of macronutrient feeding on intestinal blood flow and subsequent intestinal injury (van Wijck et al. 2014). However, it appears that pre-exercise macronutrient intake and (or) infrequent macronutrient consumption may have limited and (or) short-lived effects on splanchnic perfusion, intestinal ischemia, and subsequent intestinal epithelial injury (Sessions et al. 2016; van Wijck et al 2014). Indeed, this is supported by previous research suggesting the cessation of carbohydrate intake during prolonged ( $\geq 3 \mathrm{~h}$ ) steady state running may contribute to substantial increases in intestinal injury (i.e., up to $4443 \mathrm{pg} \cdot \mathrm{ml}^{-1}$ increase in plasma I-FABP concentration) (Costa et al. 2017b). Therefore, from a practical perspective, it may be important to recommend early and frequent macronutrient consumption during prolonged exercise to avoid intestinal epithelial injury and associated gastrointestinal implications, including impaired nutrient absorption and exacerbation of gastrointestinal symptoms (Costa et al. 2017b; Lang et al. 2006; van Wijck et al. 2013). It is also yet to be determined if lower concentrations of macronutrients consumed before and frequently during prolonged strenuous exercise results in similar outcomes (e.g., $5 \mathrm{~g}$ or 10 $\left.\mathrm{g} \cdot 20 \mathrm{~min}^{-1}\right)$

\section{Small intestine permeability}

The reduction in small intestine permeability observed on GLUC and WPH during prolonged running in the heat is a novel finding that could have important clinical outcomes. For example, increased intestinal injury and permeability is a distinct feature of many acute and chronic health conditions, and has been implicated as a primary mechanism for endotoxaemia and gastrointestinal-originated exertional heat stroke (Caradonna et al. 2000; Cohen et al. 2009; Grootjans et al. 2016; Lim and Mackinnon 2006; Rav-Acha et al. 2004). Our findings indicate that frequent macronutrient intake reduces small intestine permeability compared to WATER. These findings are supported by previous research showing ingestion of carbohydrates every $10 \mathrm{~min}$ 
during $1 \mathrm{~h}$ running at $70 \% \dot{\mathrm{VO}}_{2 \max }$ reduces aspirin-induced gastroduodenal permeability (Lambert et al. 2001). Although small intestine permeability was not reduced and there was no further benefit obtained from the addition of glutamine at a similar rate to the WPH (Lambert et al. 2001). Whereas, in the current study, energy-matched WPH was more effective than GLUC at maintaining tight junction integrity and regulation during EHS, despite similar I-FABP profiles. Indeed, longerterm (7-28 days) supplementation of whey-based proteins and amino acids (i.e., glutamine) have been associated with improvements in gastrointestinal permeability with proposed mechanisms that include increased heat shock protein expression (e.g., HSP70), stabilised tight junction protein complexes, and thus reducing localised epithelial and systemic inflammatory responses (de Moura et al. 2013; Kotler et al. 2013; Zuhl et al. 2014a). It is therefore, plausible that WPH may have further reduced small intestine permeability via increased heat shock protein expression (Zuhl et al. 2014b; Zuhl et al. 2015). Albeit, further research is required to elucidate the exact mechanisms that explain the observed differences in small intestine permeability between GLUC and WPH.

\section{Systemic endotoxin and cytokine profile}

In the current study, circulating endotoxin concentrations increased in all trials, despite a lower small intestine permeability on GLUC and WPH. The lack of a consistent relationship between intestinal permeability and circulatory endotoxin concentrations is supported by other studies, indicating factors beyond the extent of intestinal permeability such as lymphatic translocation, hepatic clearance rates, and (or) exercise-associated depression in immune function (e.g., phagocyte elastase degranulation) may contribute to mild exercise-associated endotoxaemia (Camus et al. 1998; Costa et al. 2009; Costa et al. 2011; Yeh et al. 2013). For example, gramnegative endotoxins may enter systemic circulation through the lymphatic system, rather than the paracellular route, and be bound to lipoproteins, soluble/membrane CD14 and (or) appear as outer membrane vesicles with differing clearance capacities and rates (Azuma et al. 1983; Hurley 1995; Kaparakis-Liaskos and Ferrero 2015; Munford 2016; Selkirk et al. 2008). 
Changes in endotoxin flux by measuring anti-endotoxin antibodies may, therefore, be a useful indicator of circulatory endotoxin clearance and partly predict neutralization capacity (Bennett-Guerrero et al. 2001). In the current study, anti-endotoxin antibodies were increased postEHS on GLUC and reduced on WATER, suggesting that carbohydrate intake may support endotoxin clearance, potentially through maintenance of immune function (Costa et al. 2009; Costa et al. 2011). While the higher intestinal permeability and reduced anti-endotoxin antibodies on WATER, indicate increased endotoxin translocation and clearance may have occurred, despite similar post-exercise circulatory endotoxin concentration to GLUC and WPH. Indeed, endurance training has been proposed to improve endotoxin tolerance arising from repeated endotoxin exposure (Lim et al. 2009; Selkirk et al. 2008). Therefore, the commonly observed mild endotoxaemia might be a normal physiological response to strenuous exercise and pose no additional health risk if endotoxin clearance capacity (i.e., anti-endotoxin antibodies, liver function, phagocytic immune cell function) and recovery time is adequate. For example, anti-endotoxin antibodies are often reduced following endurance and ultra-endurance events, followed by a supercompensation in antibodies during recovery, suggesting a beneficial adaptation (Camus et al. 1998; Jeukendrup et al. 2000). In addition to higher anti-endotoxin antibodies on GLUC, lower postexercise plasma cortisol and IL-6 concentrations were observed, compared to WATER, which may be attributed to the increased blood glucose levels (Henson et al. 1999; Nieman et al. 1998; Pedersen and Hoffman-Goetz 2000). Similar observation of increased blood glucose combined with reduced plasma cortisol and pro-inflammatory cytokine concentrations have previously been observed with carbohydrate intake during prolonged exercise, suggesting a reduced stress response with carbohydrate consumption compared to WATER (Henson et al. 1999; Nieman et al. 1998). These findings may have significant gastrointestinal-immune health implications, whereby repeated carbohydrate consumption during exercise may ameliorate localised gastrointestinal injury, cytokine signalling, local and systemic inflammatory responses. Moreover, active individuals adhering to low-carbohydrate diets and (or) exercising fasted in an attempt to increase fat oxidation 
and (or) avoid gastrointestinal issues may be at increased risk of exercise-associated gastrointestinal disturbances and related health implications.

\section{Gastrointestinal symptoms}

Gastrointestinal symptoms are a major medical complaint consistently affecting $>60 \%$ of runners during endurance events, especially when conducted in hot ambient conditions (Costa et al. 2016; Jeukendrup et al. 2000; Stuempfle et al. 2013; Stuempfle and Hoffman 2015). Indeed, we have recently shown that exposure to hot ambient conditions during running directly contributes to the development of gastrointestinal symptoms, compared with temperate conditions (Snipe et al. 2016). Moreover, a recent study has demonstrated that large doses $\left(90 \mathrm{~g} \cdot \mathrm{h}^{-1}\right)$ of multipletransportable carbohydrates during prolonged running, a period when the gastrointestinal tract is compromised, results in malabsorption and the onset of gastrointestinal symptoms (Costa et al. 2017b). Reductions in splanchnic blood flow during high intensity exercise, or arising from heat exposure, can impair carbohydrate absorption (Lang et al. 2006; Rehrer et al. 2005). Unabsorbed carbohydrates may contribute to the development of upper-gastrointestinal symptoms via the ileal brake mechanism that slows gastric emptying, or lower-gastrointestinal symptoms due to increased colonic content and pressure (Shin et al. 2013; Yao et al. 2016). In the current study, GLUC was provided at a similar rate (i.e., $45 \mathrm{~g} \cdot \mathrm{h}^{-1}$ ), in a readily absorbed concentration, to those reported during competitive endurance running events (Costa et al. 2016; Pfeiffer et al. 2012). No observable differences were found in gastrointestinal symptoms between GLUC and WATER, suggesting that prescribed provision of moderate carbohydrate intake does not increase gastrointestinal symptoms over ad libitum water intake, and thus is well tolerated.

While GLUC did not appear to exacerbate gastrointestinal symptoms, similar energy and volume intake of WPH increased the incidence and severity of symptoms, particularly uppergastrointestinal symptoms, compared to GLUC and WATER. The increased prevalence of symptoms such as bloating and urge to regurgitate, suggest a possible delay in gastric emptying and 
(or) altered gastrointestinal motility with WPH (Horner et al. 2015; Leiper 2015). Several other studies have also found increased reports of gastrointestinal symptoms with consumption of moderate to large protein and (or) amino acid intake before or during exercise (Gentle et al. 2014; Grimble 2007; Rehrer et al. 1992). However, hydrolysed proteins have been reported to be digested and absorbed at a faster rate than complete proteins (Koopman et al. 2009), which may have contributed to the lack of symptoms observed in a small proportion of participants in the current study. Consistent with previous research, our findings highlight large individual variability in tolerance to the type and quantity of nutrition intake during running (Costa et al. 2016; Costa et al. 2017b). It is plausible that smaller doses of WPH than provided during this study may be beneficial in maintaining gastrointestinal integrity while avoiding the occurrence of gastrointestinal symptoms, this however requires further investigation. Indeed, the occurrence of gastrointestinal symptoms during prolonged running likely arises due to the additional burden of nutrient digestion and absorption during a period of compromised gastrointestinal integrity and (or) function. Therefore, it is suggested that individual tolerance to nutrient intake during exercise be established and (or) trained for increased tolerance to optimise gastrointestinal integrity, health, and exercise performance outcomes (Costa et al. 2017b; Hansen et al. 2014).

Due to the aforementioned differences in tolerance to nutrient intake during exercise, WATER was provided ad libitum in the current study to act as a control for gastrointestinal symptoms. Despite advising participants to drink sufficient amounts of water to maintain euhydration, a limitation of the current study is the additional body mass loss $(\sim 0.9 \%)$ that occurred on WATER compared to GLUC and WPH. However, body mass losses were below values considered as modest dehydrated ( $\geq 2 \%$ exercise-induced body mass loss) and values shown to contribute to the development of gastrointestinal symptoms (Cheuvront et al. 2003; Rehrer et al. 1989). Moreover, $\mathrm{T}_{\mathrm{re}}$ and plasma osmolality were not significantly different between trials, indicating minimal effects on factors that may exacerbate gastrointestinal perturbations (e.g., thermoregulation and hydration status) (Lambert et al. 2008; Pires et al. 2016). 


\section{Conclusion and future perspectives}

Regular provision of glucose during EHS reduces intestinal injury and permeability, supports endotoxin clearance, and potentially lessens the stress response, compared to when only water is ingested. Frequent intake of hydrolysed whey protein during EHS also reduces intestinal injury and permeability compared to water intake. However, protein appears to have minimal impact on systemic responses and such large intakes appear to increase gastrointestinal symptoms compared to water and carbohydrate intake. Therefore, frequent ingestion of carbohydrates may be more appropriate to recommend for supporting gastrointestinal integrity during EHS. Future research should aim to identify the minimum carbohydrate dose and frequency required to ameliorate gastrointestinal perturbations and if these benefits exist at higher exercise intensities and (or) over longer durations. 


\section{Conflicts of interest declaration}

Peter Gibson (PG) has served as consultant or advisory board member for AbbVie, Ferring, Janssen, Merck, Nestle Health Science, Danone, Allergan, Pfizer, Celtrion and Takeda. His institution has received speaking honoraria from AbbVie, Janssen, Ferring, Takeda, Fresenius Kabi, Mylan and Pfizer. He has received research grants for investigator-driven studies from AbbVie, Janssen, Falk Pharma, Danone and A2 Milk Company. His Department financially benefits from the sales of a digital application and booklets on the low FODMAP diet. Other authors have nothing to declare.

\section{Acknowledgements}

Firstly, the authors would like to thank all the participants that volunteered to take part in this study. The authors' contributions are as follows: Ricardo Costa (RC) was the chief investigator of this research. RC, Rhiannon Snipe (RS), and PG contributed towards the original research idea and development of the experimental design. RC, RS, Anthony Khoo (AK), and Cecilia Kitic (CK) contributed to the various aspects of data collection, and sample collection and analysis. RC and RS contributed to the analysis of the raw data. All authors contributed to the preparation and review of the manuscript. All authors read and approved the final manuscript. The study was supported by Monash University, Faculty of Medicine, Nursing and Health Sciences, Faculty Strategic Grant Scheme, SGS15-0128. 


\section{References}

Azuma, K., Akiyama, M., Ebata, T., Totsuka, M., and Hayasaka, H. 1983. Endogenous endotoxin absorption and the role of intestinal lymphatics. Jpn. J. Surg. 13(6):535-9. PMID: 6672385.

Bengtsson, M., Persson, J., Sjölund, K., and Ohlsson, B. 2013. Further validation of the visual analogue scale for irritable bowel syndrome after use in clinical practice. Gastroenterol. Nurs. 36(3):188-98. doi: 10.1097/SGA.0b013e3182945881. PMID: 23732784.

Bennett-Guerrero, E., Barclay, G.R., Weng, P.L., Bodian, C.A., Feierman, D.E., Vela-Cantos, F., and Mythen, M.G. 2001. Endotoxin-neutralizing capacity of serum from cardiac surgical patients. J Cardiothorac. Vasc. Anesth. 15(4):451-4. PMID: 11505348.

Borg, G.A. 1982. Psychophysical bases of perceived exertion. Med. Sci. Sports Exerc. 14(5):37781. PMID: 7154893.

Camus, G., Nys, M., Poortmans, J.R., Venneman, I., Monfils, T., Deby-Dupont, G. et al. 1998. Endotoxaemia, production of tumour necrosis factor $\alpha$ and polymorphonuclear neutrophil activation following strenuous exercise in humans. Eur. J. Appl. Physiol. Occup. Physiol. 79(1):62-8. PMID: 10052662.

Caradonna, L., Amati, L., Magrone, T., Pellegrino, N.M., Jirillo, E., and Caccavo, D. 2000. Enteric bacteria, lipopolysaccharides and related cytokines in inflammatory bowel disease: biological and clinical significance. J. Endotoxin. Res. 6(3):205-14. PMID: 11052175.

Cheuvront, S.N., Carter, R. 3rd, and Sawka, M.N. 2003. Fluid balance and endurance exercise performance. Curr. Sports Med. Rep. 2(4):202-8. PMID: 12834575.

Cohen, D.C., Winstanley, A., Engledow, A., Windsor, A.C., and Skipworth, J.R. 2009. Marathoninduced ischemic colitis: why running is not always good for you. Am. J. Emerg. Med. 27(2):255.e5-7. doi: 10.1016/j.ajem.2008.06.033. PMID: 19371557. 
Costa, R.J., Crockford, M.J., Moore, J.P., and Walsh, N.P. 2014. Heat acclimation responses of an ultra-endurance running group preparing for hot desert-based competition. Eur. J. Sport Sci. 14(suppl 1):S131-41. doi: 10.1080/17461391.2012.660506. PMID: 24444197.

Costa, R.J.S., Miall, A., Khoo, A., Rauch, C., Snipe, R., Camões-Costa, V. et al. 2017b. Guttraining: The impact of two weeks repetitive gut-challenge during exercise on gastrointestinal status, glucose availability, fuel kinetics, and running performance. Appl. Physiol. Nutr. Metab. 42(5):547-57. doi: 10.1139/apnm-2016-0453. PMID: 28177715.

Costa, R.J., Oliver, S.J., Laing, S.J., Waiters, R., Bilzon, J.L., and Walsh, N.P. 2009. Influence of timing of postexercise carbohydrate-protein ingestion on selected immune indices. Int. J. Sport Nutr. Exerc. Metab. 19(4):366-84. PMID: 19827462.

Costa, R.J., Snipe, R., Camões-Costa, V., Scheer, V., and Murray, A. 2016. The impact of gastrointestinal symptoms and dermatological injuries on nutritional intake and hydration status during ultramarathon events. Sports Med. Open. 2:16. doi 10.1186/s40798-015-0041-9. PMID: 26767151.

Costa, R.J.S., Snipe, R., Kitic, C., and Gibson, P., 2017a. Systematic review: Exercise-induced gastrointestinal syndrome- Implication for health and disease. Alim. Therap. Pharmacol. 46(3):24665. doi: 10.1111/apt.14157. PMID: 28589631.

Costa, R.J.S., Walters, R., Bilzon, J.L.J., and Walsh, N.P. 2011. Effects of immediate postexercise carbohydrate ingestion with and without protein on neutrophil degranulation. Int. J. Sport. Nutr. Exerc. Metab. 21(3):205-13. PMID: 21719901.

de Moura, C.S., Lollo, P.C.B., Morato, P.N., Carneiro, E.M., and Amaya-Farfan, J. 2013. Whey protein hydrolysate enhances the exercise-induced heat shock protein (HSP70) response in rats. Food Chem. 136:1350-57. doi: 10.1016/j.foodchem.2012.09.070. PMID: 23194534. 
Dokladny, K., Moseley, P.L., and Ma, T.Y. 2006. Physiologically relevant increase in temperature causes an increase in intestinal epithelial tight junction permeability. Am. J. Physiol. Gastrointest. Liver Physiol. 290(2):G204-12. doi. 10.1152/ajpgi.00401.2005. PMID: 16407590.

Gentle, H.L., Love, T.D., Howe, A.S., and Black, K.E. 2014. A randomised trial of pre-exercise meal composition on performance and muscle damage in well-trained basketball players. J. Int. Soc. Sports Nutr. 11:33. doi: 10.1186/1550-2783-11-33. PMID: 25053925.

Gill, S.K., Allerton, D.M., Ansley-Robson, P., Hemming, K., Cox, M., \& Costa, R.J.S. 2016. Does acute high dose probiotic supplementation containing lactobacillus casei attenuate exertional-heat stress induced endotoxaemia and cytokinaemia? Int. J. Sports Nutr. Exerc. Metab. 26:268-75. doi.org/10.1123/ijsnem.2015-0186. PMID: 26568577.

Gill, S.K., Hankey, J., Wright, A., Marczak, S., Hemming, K., Allerton, D.M. et al. 2015a. The impact of a 24-h ultra-marathon on circulatory endotoxin and cytokine profile. Int. J. Sports. Med. 36(8):688-95. doi: 10.1055/s-0034-1398535. PMID: 25941924.

Gill, S.K., Teixeira, A., Rama, L., Prestes, J., Rosado, F., Hankey, J. et al. 2015b. Circulatory endotoxin concentration and cytokine profile in response to exertional-heat stress during a multistage ultra-marathon competition. Exerc. Immunol. Rev. 21:114-28. PMID: 25830597

Grootjans, J., Lenaerts, K., Buurman, W.A., Dejong, C.H., and Derikx, J.P. 2016. Life and death at the mucosal-luminal interface: new perspectives on human intestinal ischemia-reperfusion. World J. Gastroenterol. 22: 2760-70. doi: 10.3748/wjg.v22.i9.2760. PMID: 26973414.

Grimble, G.K. 2007. Adverse gastrointestinal effects of arginine and related amino acids. J. Nutr. 137(6 Suppl 2):1693S-1701S. PMID: 17513449.

Hansen, E.A., Emanuelsen, A., Gertsen, R.M., and Sørensen, S.S.R. 2014. Improved marathon performance by in-race nutritional strategy intervention. Int. J. Sport Nutr. Exerc. Metab. 24(6):64555. doi: 10.1123/ijsnem.2013-0130. PMID: 24901444. 
Henson, D.A., Nieman, D.C., Blodgett, A.D., Butterworth, D.E., Utter, A., Davis, J.M., Sonnenfeld, G., Morton, D.S., Fagoaga, O.R., and Nehlsen-Cannarella, S.L. 1999. Influence of exercise mode and carbohydrate on the immune response to prolonged exercise. Int. J. Sport. Nutr. 9(2):213-28. PMID: 10428573.

Hoffman, M.D., and Fogard, K. 2011. Factors related to successful completion of a 161-km ultramarathon. Int. J. Sports Physiol. Perform. 6(1):25-37. PMID: 21487147.

Hollies, N.R.S., and Goldman, R.F. 1977. Psychological scaling in comfort assessment. In: Hollies NRS, Goldman RF (ed.) Clothing comfort: Interaction of thermal, ventilation, construction, and assessment factors. Ann Arbor Science Publishers Inc. Michigan, USA, pp 107-20.

Horner, K.M., Schubert, M.M., Desbrow, B., Byrne, N.M., and King, N.A. 2015. Acute exercise and gastric emptying: a meta-analysis and implications for appetite control. Sports Med. 45(5):65978. doi: 10.1007/s40279-014-0285-4. PMID: 25398225.

Hurley, J.C. 1995. Endotoxemia: methods of detection and clinical correlates. Clin. Microbiol. Rev. 8(2):268-92. PMID: 7621402.

Jeukendrup, A.E., Vet-Joop, K., Sturk, A., Stegen, J.H., Senden, J., Saris, W.H. et al. 2000. Relationship between gastro-intestinal complaints and endotoxaemia, cytokine release and the acute-phase reaction during and after a long-distance triathlon in highly trained men. Clin. Sci. (Lond) 98(1):47-55. PMID: 10600658.

Kaparakis-Liaskos, M., and Ferrero, R.L. 2015. Immune modulation by bacterial outer membrane vesicles. Nat. Rev. Immunol. 15: 375-87. doi: 10.1038/nri3837. PMID: 25976515.

Koopman, R., Crombach, N., Gijsen, A.P., Walrand, S., Fauquant, J., Kies, A.K., Lemosquet, S., Saris, W.H., Boirie, Y., and van Loon, L.J. 2009. Ingestion of a protein hydrolysate is accompanied by an accelerated in vivo digestion and absorption rate when compared with its intact protein. Am. J. Clin. Nutr. 90:106-15. doi: 10.3945/ajen.2009.27474. PMID: 19474134. 
Kotler, B.M., Kerstetter, J.E., and Insogna, K.L. 2013. Claudins, dietary milk proteins, and intestinal barrier regulation. Nutr. Rev. 71(1):60-5. doi: 10.1111/j.1753-4887.2012.00549.x. PMID: 23282252.

Lambert, G.P., Broussard, L.J., Mason, B.L., Mauermann, W.J., and Gisolfi, C.V. 2001. Gastrointestinal permeability during exercise: effects of aspirin and energy-containing beverages. J. Appl. Physiol. 90:2075-80. PMID: 11356768.

Lambert, G.P., Lang, J., Bull, A., Eckerson, J., Lanspa, S., and O’Brien, J. 2008a. Fluid tolerance while running: effect of repeated trials. Int. J. Sports Med. 29(11):878-82. doi: 10.1055/s-20081038620. PMID: 18512180.

Lambert, G.P., Lang, J., Bull, A., Pfeifer, P.C., Eckerso, J., Moore, C. et al. 2008b. Fluid restriction during running increases Gl permeability. Int. J. Sports Med. 29(3):194-8. doi. 10.1055/s-2007965163

Lang, J.A., Gisolfi, C.V., and Lambert, G.P. 2006. Effect of exercise intensity on active and passive glucose absorption. Int. J. Sport Nutr. Exerc. Metab. 16(5):485-93. PMID: 17240781.

Leiper, J.B. 2015. Fate of ingested fluids: factors affecting gastric emptying and intestinal absorption of beverages in humans. Nutr. Rev. 73 Suppl 2:57-72. PMID: 26290292.

Lim, C.L., and Mackinnon, L.T. 2006. The roles of exercise-induced immune system disturbances in the pathology of heat stroke : the dual pathway model of heat stroke. Sports Med. 36(1):39-64. PMID: 16445310.

Lim, C.L., Pyne, D., Horn, P., Kalz, A., Sauders, P., Peake, J. et al. 2009. The effects of increased endurance training load on biomarkers of heat intolerance during intense exercise in the heat. Appl. Physiol. Nutr. Metab. 34(4):616-24. doi: 10.1139/H09-021. PMID: 19767796.

Lis, D., Ahuja, K.D., Stellingwerff, T., Kitic, C.M., and Fell, J. 2016. Food avoidance in athletes: FODMAP foods on the list. Appl. Physiol. Nutr. Metab. 41(9):1002-4. doi: 10.1139/apnm-20150428. PMID: 27507006. 
Matheson, P.J., Wilson, M.A., and Garrison, R.N. 2000. Regulation of intestinal blood flow. J. Surg. Res. 93:182-96. PMID: 10945962.

Morris, G., Berk, M., Galecki, P., and Maes, M. 2014. The emerging role of autoimmunity in myalgic encephalomyelitis/chronic fatigue syndrome (ME/cfs). Mol. Neurobiol. 49(2):741-56. doi: 10.1007/s12035-013-8553-0. PMID: 24068616.

Munford, R.S. 2016. Endotoxemia-menace, marker, or mistake? J. Leukoc. Biol.100(4):687-98. doi: 10.1189/jlb.3RU0316-151R. PMID: 27418356.

Nieman, D.C., Nehlsen-Cannarella, S.L., Fagoaga, O.R., Henson, D.A., Utter, A., Davis, J.M., Williams, F., and Butterworth, D.E. 1998. Influence of mode and carbohydrate on the cytokine response to heavy exertion. Med. Sci. Sports Exerc. 30(5):671-8. PMID: 9588607.

Pedersen, B.K., and Hoffman-Goetz, L. 2000. Exercise and the immune system: regulation, integration, and adaptation. Physiol. Rev. 80(3):1055-81. PMID: 10893431.

Pfeiffer, B., Stellingwerff, T., Hodgson, A.B., Randell, R., Pöttgen, K., Res, P., and Jeukendrup, A.E. 2012. Nutritional intake and gastrointestinal problems during competitive endurance events. Med. Sci. Sports Exerc. 44(2):344-51. doi: 10.1249/MSS.0b013e31822dc809. PMID: 21775906.

Pires, W., Veneroso, C.E., Wanner, S.P., Pacheco, D.A., Vaz, G.C., Amorim, F.T. et al. 2016. Association Between exercise-induced hyperthermia and intestinal permeability: a systematic review. Sports Med. 47(7):1389-403. doi: 10.1007/s40279-016-0654-2. PMID: 27943148.

Qamar, M.I., and Read, A.E. 1987. Effects of exercise on mesenteric blood flow in man. Gut. 28:583-87. PMID: 3596339.

Rav-Acha, M., Hadad, E., Epstein, Y., Heled, Y., and Moran, DS. 2004. Fatal exertional heat stroke: a case series. Am. J. Med. Sci. 328(2):84-7. PMID: 15311166. 
Rehrer, N.J., Goes, E., Du Gardeyn, C., Reynaert, H., and DeMeirleir, K. 2005. Effect of carbohydrate on portal vein blood flow during exercise. Int. J. Sports Med. 26(3):171-6. PMID: 15776331.

Rehrer, N.J., Janssen, G.M., Brouns, F., and Saris, W.H. 1989. Fluid intake and gastrointestinal problems in runners competing in a $25-\mathrm{km}$ race and a marathon. Int. J. Sports Med. 10(Suppl 1):S22-5. doi: 10.1055/s-2007-1024950. PMID: 2744925.

Rehrer, N.J., van Kemenade, M., Meester, W., Brouns, F., and Saris, W.H. 1992. Gastrointestinal complaints in relation to dietary intake in triathletes. Int. J. Sport Nutr. 2(1):48-59. PMID: 1338583. Sanchez, L.D., Tracy, J.A., Berkoff, D., and Pedrosa, I. 2006. Ischemic colitis in marathon runners: a case-based review. J. Emerg. Med. 30(3):321-6. doi: 10.1016/j.jemermed.2005.05.21. PMID: 16677987.

Selkirk, G.A., McLellan, T.M., Wright, H.E., and Rhind, S.G. 2008. Mild endotoxemia, NF-kappaB translocation, and cytokine increase during exertional heat stress in trained and untrained individuals. Am. J. Physiol. Regul. Integr. Comp. Physiol. 295(2):R611-23. doi: 10.1152/ajpregu.00917.2007. PMID: 18565834.

Sessions, J., Bourbeau, K., Rosinski, M., Szczygiel, T., Nelson, R., Sharma, N. et al. 2016 Carbohydrate gel ingestion during running in the heat on markers of gastrointestinal distress. Eur $\mathrm{J}$ Sport Sci. 16(8):1064-72. doi: 10.1080/17461391.2016.1140231. PMID: 26841003.

Shin, H.S., Ingram, J.R., McGill, A.T., and Poppitt, S.D. 2013 Lipids, CHOs, proteins: can all macronutrients put a 'brake' on eating? Physiol. Behav. 120:114-23. doi: 10.1016/j.physbeh.2013.07.008. PMID: 23911804.

Snipe, R., Kitic, C., Gibson, P., and Costa, R.J.S. 2016. Heat stress during prolonged running results in exacerbated intetsinal epithelial injury and gastrointestinal symptoms. In Proceedings of the Research to Prcatice 2016 Conference, Melbourne Convention and Exhibition Centre, 14-16 April 2016. Edited by Exercise \& Sports Science Australia, Qld, Australia. pp. 168. 
Stellingwerff, T., and Cox, G.R. 2014. Systematic review: Carbohydrate supplementation on exercise performance or capacity of varying durations Appl. Physiol. Nutr. Metab. 39(9):998-1011. doi: 10.1139/apnm-2014-0027. PMID: 24951297.

Stuempfle, K.J., and Hoffman, M.D. 2015. Gastrointestinal distress is common during a 161-km ultramarathon. J. Sports Sci. 33(17):1814-21. doi: 10.1080/02640414.2015.1012104. PMID: 25716739.

Stuempfle, K.J., Hoffman, M.D., and Hew-Butler, T. 2013. Association of gastrointestinal distress in ultramarathoners with race diet. Int. J. Sport Nutr. Exerc. Metab. 23(2):103-9. PMID: 23006626. van Nieuwenhoven, M.A., Brummer, R.M., and Brouns, F. 2000. Gastrointestinal function during exercise: comparison of water, sports drink, and sports drink with caffeine. J. Appl. Physiol. 89(3):1079-85. PMID: 10956354.

van Wijck, K., Lenaerts, K., Grootjans, J., Wijnands, K.A.P., Poeze, M., van Loon, L.J.C. et al. 2012. Physiology and pathophysiology of splanchnic hypoperfusion and intestinal injury during exercise: Strategies for evaluation and prevention. Am. J. Physiol. Gastrointest. Liver Physiol. 303(2):G155-G68. doi: 10.1152/ajpgi.00066.2012. PMID: 22517770.

van Wijck, K., Lenaerts, K., van Loon, L.J.C., Peters, W.H.M., Buurman, W.A., and Dejong, C.H.C 2011. Exercise-Induced splanchnic hypoperfusion results in gut dysfunction in healthy men. PLoS ONE. 6(7):e22366. doi: 10.1371/journal.pone.0022366. PMID: 21811592.

van Wijck, K., Pennings, B., van Bijnen, A.A., Senden, J.M., Buurman, W.A., Dejong, C.H. et al 2013. Dietary protein digestion and absorption are impaired during acute postexercise recovery in young men. Am. J. Physiol. Regul. Integr. Comp. Physiol. 304(5):R356-61. doi: 10.1152/ajpregu.00294.2012. PMID: 23283940.

van Wijck K., Wijnands K.A., Meesters D.M., Boonen B., van Loon L.J., Buurman W.A., Dejong C.H., Lenaerts K., and Poeze M. 2014. L-citrulline improves splanchnic perfusion and reduces gut 
injury during exercise. Med. Sci. Sports Exerc. 46:2039-46. doi: 10.1249/MSS.0000000000000332. PMID: 24621960.

Yao, C.K, Muir, J.G, and Gibson, P.R. 2016. Review article: insights into colonic protein fermentation, its modulation and potential health implications. Aliment. Pharmacol. Ther. 43(2): 181-96. doi: 10.1111/apt.13456. PMID: 26527169.

Yeh, Y., Law, L., and Lim, C. 2013. Gastrointestinal response and endotoxemia during intense exercise in hot and cool environments. Eur. J. Appl. Physiol. 113(6):1575-83. doi: 10.1007/s00421013-2587-x. PMID: 23314685.

Zuhl, M., Dokladny, K., Mermier, C., Schneider, S., Salgado, R., and Moseley, P. 2015. The effects of acute oral glutamine supplementation on exercise-induced gastrointestinal permeability and heat shock protein expression in peripheral blood mononuclear cells. Cell Stress Chaperones. 20(1):8593. doi: 10.1007/s12192-014-0528-1. PMID: 25062931.

Zuhl, M.N., Lanphere, K.R., Kravitz, L., Mermier, C.M., Schneider, S., Dokladny, K., Moseley, P.L. 2014a. Effects of oral glutamine supplementation on exercise-induced gastrointestinal permeability and tight junction protein expression. J. Appl. Physiol. 116(2):183-91. doi: 10.1152/japplphysiol.00646.2013. PMID: 24285149.

Zuhl, M., Schneider, S., Lanphere, K., Conn, C., Dokladny, K., and Moseley, P. 2014b. Exercise regulation of intestinal tight junction proteins. Br. J. Sports Med. 48(12):1-9. doi: 10.1136/bjsports2012-091585. PMID: 23134759. 


\section{Pag}

Table 1. Water intake, body mass loss and plasma osmolality in response to $2 \mathrm{~h}$ running at $60 \% \dot{\mathrm{VO}_{2 \max }}$ in $35^{\circ} \mathrm{C} \mathrm{T}_{\text {amb }}$ (exertional-heat stress: EHS) with ingestion of glucose (GLUC), whey protein hydrolysate (WPH) and water (WATER).

\begin{tabular}{|c|c|c|c|c|c|c|c|}
\hline & \multicolumn{2}{|c|}{ GLUC } & \multicolumn{2}{|c|}{ WPH } & \multicolumn{2}{|c|}{ WATER } & \multirow{2}{*}{$\begin{array}{l}\text { ANOVA } \\
p \text {-value }\end{array}$} \\
\hline & Pre-EHS & Post-EHS & Pre-EHS & Post-EHS & Pre-EHS & Post-EHS & \\
\hline $\begin{array}{l}\text { Total water intake } \\
\text { (L) }\end{array}$ & NA & $1.84(1.66-2.03)^{\mathrm{aa}}$ & NA & $1.89(1.64-2.15)^{\mathrm{aa}}$ & NA & $1.59(1.30-1.88)$ & 0.005 \\
\hline $\begin{array}{l}\text { Body mass loss } \\
(\%)\end{array}$ & NA & $0.5(-0.1-1.2)^{\mathrm{aa}}$ & NA & $0.4(-0.1-1.0)^{\mathrm{aa}}$ & NA & $1.3(1.0-1.6)$ & 0.000 \\
\hline $\begin{array}{l}\text { Plasma Osmolality } \\
\left(\mathrm{mOsmol} \cdot \mathrm{kg}^{-1}\right)\end{array}$ & $285(277-293)$ & $284(275-294)$ & $287(280-295)$ & $290(281-298)$ & $290(284-297)$ & $291(284-298)$ & 0.393 \\
\hline
\end{tabular}




\begin{tabular}{|c|c|c|c|c|c|c|c|}
\hline \multicolumn{8}{|c|}{$\begin{array}{l}\text { Table 2. Incidence of severe gastrointestinal symptoms and severity of gut discomfort, total, upper-, and lower-gastrointestinal sympto } \\
\text { to } 2 \mathrm{~h} \text { running at } 60 \% \dot{\mathrm{VO}}_{2 \max } \text { in } 35^{\circ} \mathrm{C} \mathrm{T}_{\mathrm{amb}} \text { with ingestion of glucose (GLUC), whey protein hydrolysate (WPH) and water (WATER). }\end{array}$} \\
\hline & \multicolumn{2}{|c|}{ GLUC } & \multicolumn{2}{|c|}{ WPH } & \multicolumn{2}{|c|}{ WATER } & \multirow{2}{*}{$\begin{array}{c}\text { Friedman } \\
p \text {-value }\end{array}$} \\
\hline & Incidence $^{1}$ & Total & Incidence $^{1}$ & Total & Incidence $^{1}$ & Total & \\
\hline Gut discomfort & NA & $402(11-58)$ & NA & $516(1-88)^{\mathrm{aa}}$ & NA & $286(0-67)$ & 0.003 \\
\hline Total gastrointestinal symptoms & $73 \%$ & $641(4-153)$ & $91 \%$ & $1370(14-269)^{\mathrm{aabb}}$ & $82 \%$ & $875(0-254)$ & 0.003 \\
\hline Upper-gastrointestinal symptoms & $45 \%$ & $362(3-90)$ & $91 \%$ & $861(0-167)^{\mathrm{aabb}}$ & $45 \%$ & $378(0-128)$ & 0.002 \\
\hline Belching & $27 \%$ & $149(0-41)$ & $45 \%$ & $267(0-48)$ & $18 \%$ & $94(0-33)$ & 0.058 \\
\hline Heartburn & $0 \%$ & $6(0-4)$ & $9 \%$ & $18(0-18)$ & $0 \%$ & $25(0-17)$ & 0.607 \\
\hline Bloating & $9 \%$ & $122(0-29)$ & $64 \%$ & $311(0-71)^{\mathrm{aabb}}$ & $18 \%$ & $106(0-40)$ & 0.001 \\
\hline Upper abdominal pain & $0 \%$ & $21(0-7)$ & $9 \%$ & $93(0-21)$ & $0 \%$ & $53(0-28)$ & 0.066 \\
\hline Urge to regurgitate & $9 \%$ & $64(0-27)$ & $45 \%$ & $172(0-40)^{b}$ & $18 \%$ & $90(0-48)$ & 0.034 \\
\hline Regurgitation & $0 \%$ & $0(0-0)$ & $0 \%$ & $0(0-0)$ & $9 \%$ & $10(0-10)$ & 0.368 \\
\hline Lower-gastrointestinal symptoms & $27 \%$ & $135(0-45)$ & $45 \%$ & $201(0-45)$ & $18 \%$ & $156(0-39)$ & 0.338 \\
\hline Flatulence & $0 \%$ & $3(0-3)$ & $0 \%$ & $28(0-25)$ & $0 \%$ & $6(0-2)$ & 0.424 \\
\hline Urge to defecate & $0 \%$ & $58(0-36)$ & $9 \%$ & $56(0-36)$ & $0 \%$ & $83(0-29)$ & 0.130 \\
\hline Abdominal pain/s & $0 \%$ & $29(0-9)$ & $18 \%$ & $72(0-22)$ & $0 \%$ & $30(0-15)$ & 0.417 \\
\hline Abnormal defecation ${ }^{2}$ & $0 \%$ & $0(0-0)$ & $0 \%$ & $0(0-0)$ & $0 \%$ & $0(0-0)$ & --- \\
\hline
\end{tabular}




\section{Pa्g}

\begin{tabular}{|c|c|c|c|c|c|c|c|}
\hline \multicolumn{8}{|l|}{ Others } \\
\hline Nausea & $9 \%$ & $82(0-38)$ & $36 \%$ & $177(0-53)$ & $27 \%$ & $155(0-43)$ & 0.210 \\
\hline Dizziness & $9 \%$ & $48(0-30)^{\mathrm{a}}$ & $18 \%$ & $72(0-37)^{\mathrm{a}}$ & $27 \%$ & $155(0-43)$ & 0.003 \\
\hline Abdominal stitch & $0 \%$ & $14(0-6)$ & $27 \%$ & $59(0-22)$ & $0 \%$ & $37(0-17)$ & 0.582 \\
\hline Appetite & NA & $180(0-53)$ & NA & $120(0-41)^{\mathrm{ab}}$ & NA & $198(0-50)$ & 0.020 \\
\hline Thirst & NA & $397(6-80)^{\mathrm{a}}$ & NA & $344(1-66)^{\mathrm{aa}}$ & NA & $520(20-87)$ & 0.006 \\
\hline
\end{tabular}

Overall participant summative accumulation of rating scale point score of measured time periods and individual participant range $(n=11) .{ }^{\text {aa }} p<0.01$ and $^{\mathrm{a}} p<0.05$ vs WATER, ${ }^{\mathrm{bb}} p<0.01$ and $^{\mathrm{b}} p<0.05$ vs GLUC. ${ }^{1}$ Incidence of severe ( $\geq 5$ out of 10 ) gastrointestinal symptoms and ${ }^{2}$ abnormal defecation including loose watery stools, diarrhoea and blood in stools. NA: not applicable. 


\section{Figure Legends}

2 Figure 1. Rectal temperature (A), heart rate (B), rating of perceived exertion (C), and thermal 3 comfort rating (D) in response to $2 \mathrm{~h}$ running at $60 \% \dot{\mathrm{VO}}_{2 \max }$ in $35^{\circ} \mathrm{C} \mathrm{T}_{\mathrm{amb}}$ on glucose (GLUC:

4 white squares), hydrolysed whey protein (WPH: grey squares) or water (WATER: black squares).

$5 \quad$ Mean $\pm \operatorname{SEM}(n=11)$ : $\dagger \dagger$ main effect of time $p<0.01$ vs. $10 \mathrm{~min}$.

6

7

8

9

10

11

12

13

14

15

16

17

18

19

20

21

22

23

24

25

26

Figure 2. Change in plasma cortisol (A) and blood glucose (B) in response to $2 \mathrm{~h}$ running at $60 \%$ $\dot{\mathrm{V}} \mathrm{O}_{2 \max }$ in $35^{\circ} \mathrm{C} \mathrm{T}_{\mathrm{amb}}$ on glucose (GLUC: white squares), hydrolysed whey protein (WPH: grey squares) or water (WATER: black squares). Mean \pm SEM (A) and mean and individual responses (B) $(n=11):{ }^{* *} p<0.01$ and ${ }^{*} p<0.05$ vs. pre-EHS, ${ }^{\text {aa }} p<0.01$ and ${ }^{\text {a }} p<0.05$ vs. WATER, ${ }^{\text {bb }} p<0.01$ vs. WPH.

Figure 3. Change in plasma intestinal fatty acid binding protein (I-FABP) in response to $2 \mathrm{~h}$ running at $60 \% \dot{\mathrm{V}}_{2 \max }$ in $35^{\circ} \mathrm{C} \mathrm{T}_{\mathrm{amb}}$ on glucose (GLUC: white squares), hydrolysed whey protein (WPH: grey squares) or water (WATER: black squares). Mean $\pm \operatorname{SEM}(n=11){ }^{* *} p<0.01$ vs. preEHS, ${ }^{\text {aa }} p<0.01$ and ${ }^{\mathrm{a}} p<0.05 v s$. WATER.

Figure 4: EHS-induced small intestine permeability (lactulose:L-rhamnose ratio) in response to $2 \mathrm{~h}$ running at $60 \% \dot{\mathrm{VO}}_{2 \max }$ in $35^{\circ} \mathrm{C} \mathrm{T}_{\mathrm{amb}}$ on glucose (GLUC), hydrolysed whey protein (WPH) or water (WATER). Mean $\pm \operatorname{SEM}(n=8):{ }^{\text {aa }} p<0.01$ vs. WATER, ${ }^{\mathrm{b}} p<0.05$ vs. GLUC.

Figure 5: Pre- to post-EHS circulatory gram-negative bacterial endotoxin (A) and anti-endotoxin antibody (B) concentration in response to $2 \mathrm{~h}$ running exercise at $60 \% \dot{\mathrm{VO}}_{2 \max }$ in $35^{\circ} \mathrm{C} \mathrm{T}_{\mathrm{amb}}$ on glucose (GLUC), hydrolysed whey protein (WPH) or water (WATER). Mean and individual responses $(n=9)$ : $\dagger$ main effect of time $p<0.05 v s$. pre-EHS, ${ }^{* *} p<0.01 v s$. pre-EHS, ${ }^{\text {aa }} p<0.01 v s$. WATER. 
28 Figure 6: Pre- and post-EHS plasma IL-6 (A), IL-1 $\beta$ (B), TNF- $\alpha$ (C), IL-8 (D), IL-10 (E), and IL29 1ra (F) concentrations in response to $2 \mathrm{~h}$ running exercise at $60 \% \dot{\mathrm{VO}}_{2 \max }$ in $35^{\circ} \mathrm{C} \mathrm{T}_{\mathrm{amb}}$ on glucose 30 (GLUC), hydrolysed whey protein (WPH) or water (WATER). Individual responses $(n=9): \dagger \dagger$ 31 main effect of time $p<0.01$ pre-EHS $v s$. post-EHS, $* * p<0.01 v s$. pre-EHS, ${ }^{a} p<0.05 v s$. WATER. 


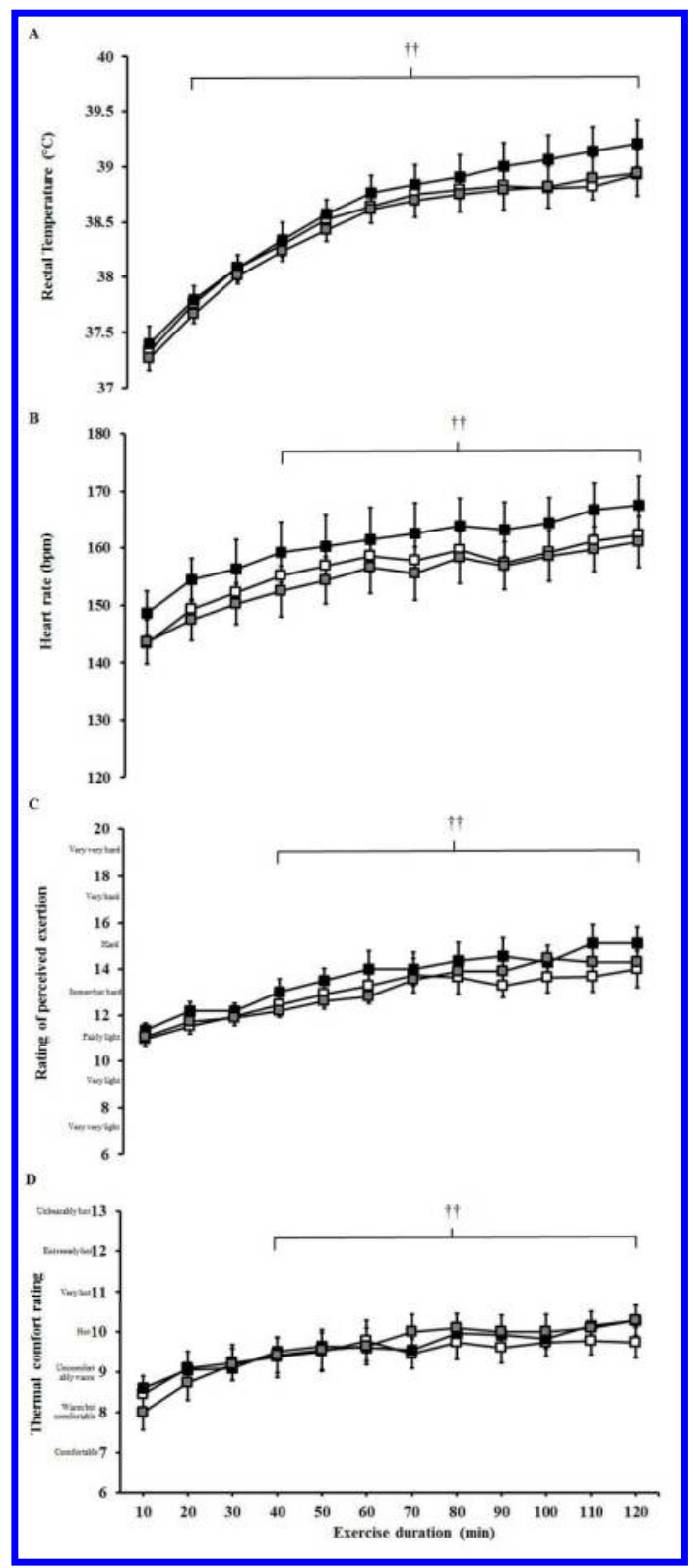

Figure 1. Rectal temperature $(A)$, heart rate $(B)$, rating of perceived exertion $(C)$, and thermal comfort rating (D) in response to $2 \mathrm{~h}$ running at $60 \%$ VO2max in $35^{\circ} \mathrm{C}$ Tamb on glucose (GLUC: white squares), hydrolysed whey protein (WPH: grey squares) or water (WATER: black squares). Mean \pm SEM $(n=11)$ : †† main effect of time $p<0.01$ vs. 10 min.

$73 \times 171 \mathrm{~mm}(300 \times 300 \mathrm{DPI})$ 


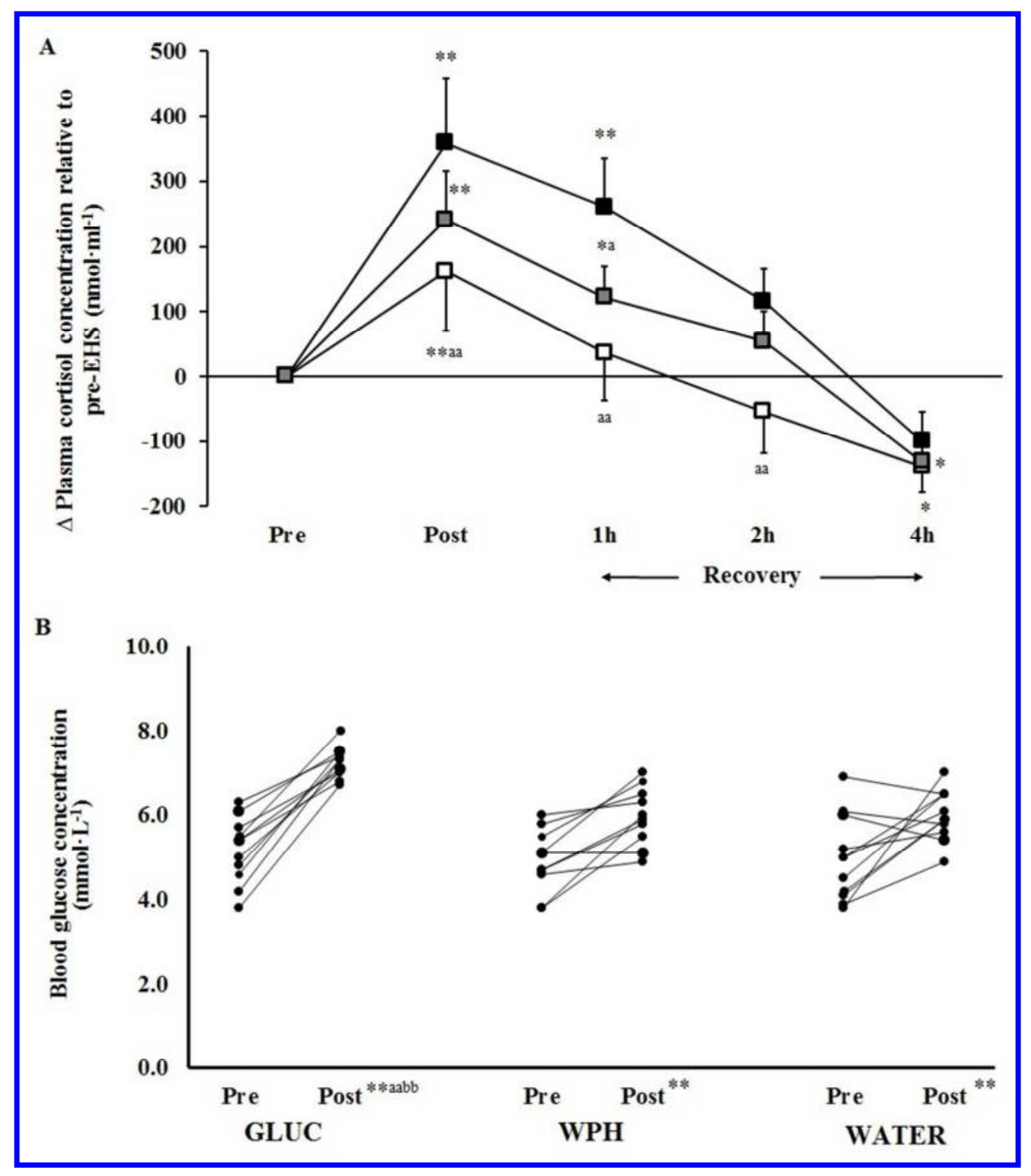

Figure 2. Change in plasma cortisol (A) and blood glucose (B) in response to $2 \mathrm{~h}$ running at $60 \%$ VO2max in $35^{\circ} \mathrm{C}$ Tamb on glucose (GLUC: white squares), hydrolysed whey protein (WPH: grey squares) or water (WATER: black squares). Mean \pm SEM $(A)$ and mean and individual responses $(B)(n=11): * * p<0.01$ and $* p<0.05$ vs. pre-EHS, aa $p<0.01$ and a $p<0.05$ vs. WATER, bb $p<0.01$ vs. WPH.

$$
73 \times 84 \mathrm{~mm}(300 \times 300 \text { DPI })
$$




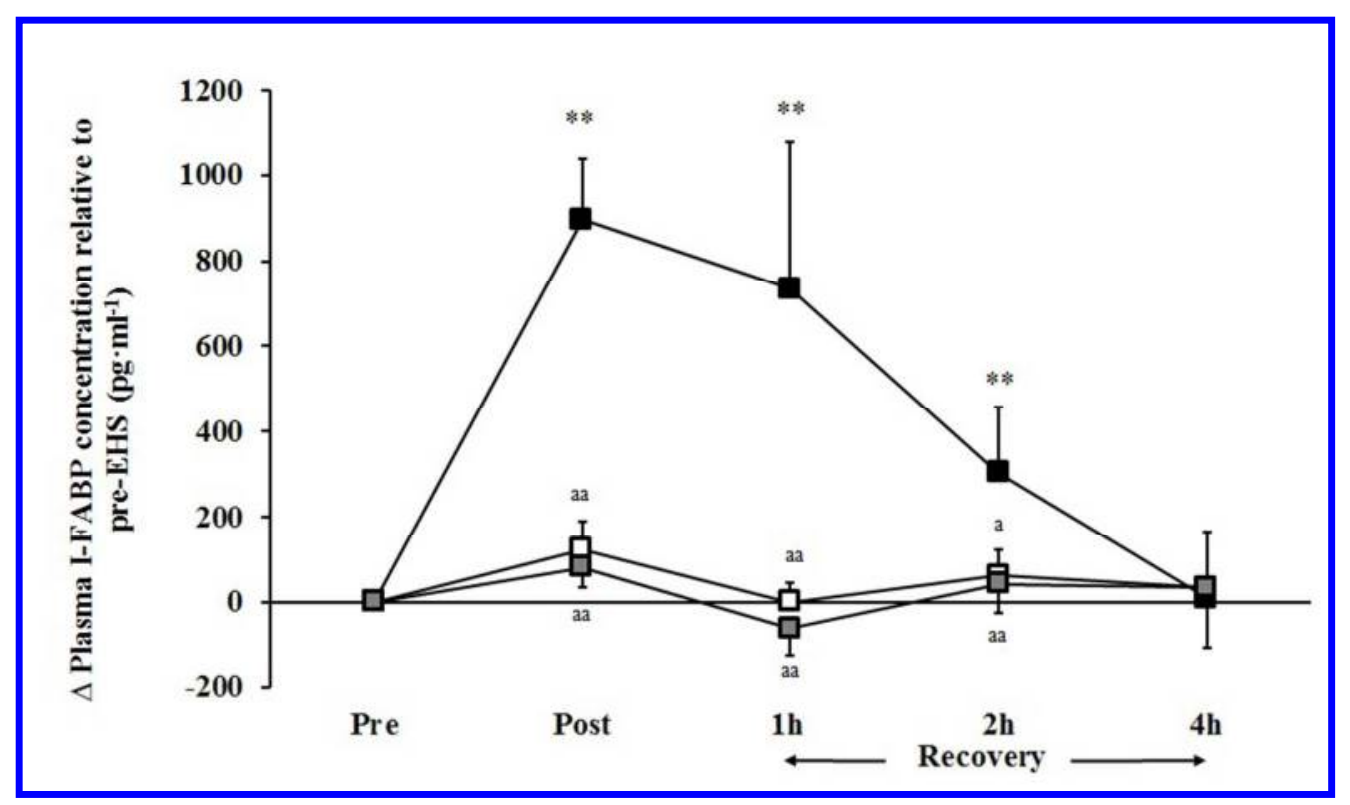

Figure 3. Change in plasma intestinal fatty acid binding protein (I-FABP) in response to $2 \mathrm{~h}$ running at $60 \%$ VO2max in $35^{\circ} \mathrm{C}$ Tamb on glucose (GLUC: white squares), hydrolysed whey protein (WPH: grey squares) or water (WATER: black squares). Mean \pm SEM $(n=11)$ : ** $p<0.01$ vs. pre-EHS, aa $p<0.01$ and a $p<0.05$ vs. WATER.

$73 \times 42 \mathrm{~mm}(300 \times 300 \mathrm{DPI})$ 


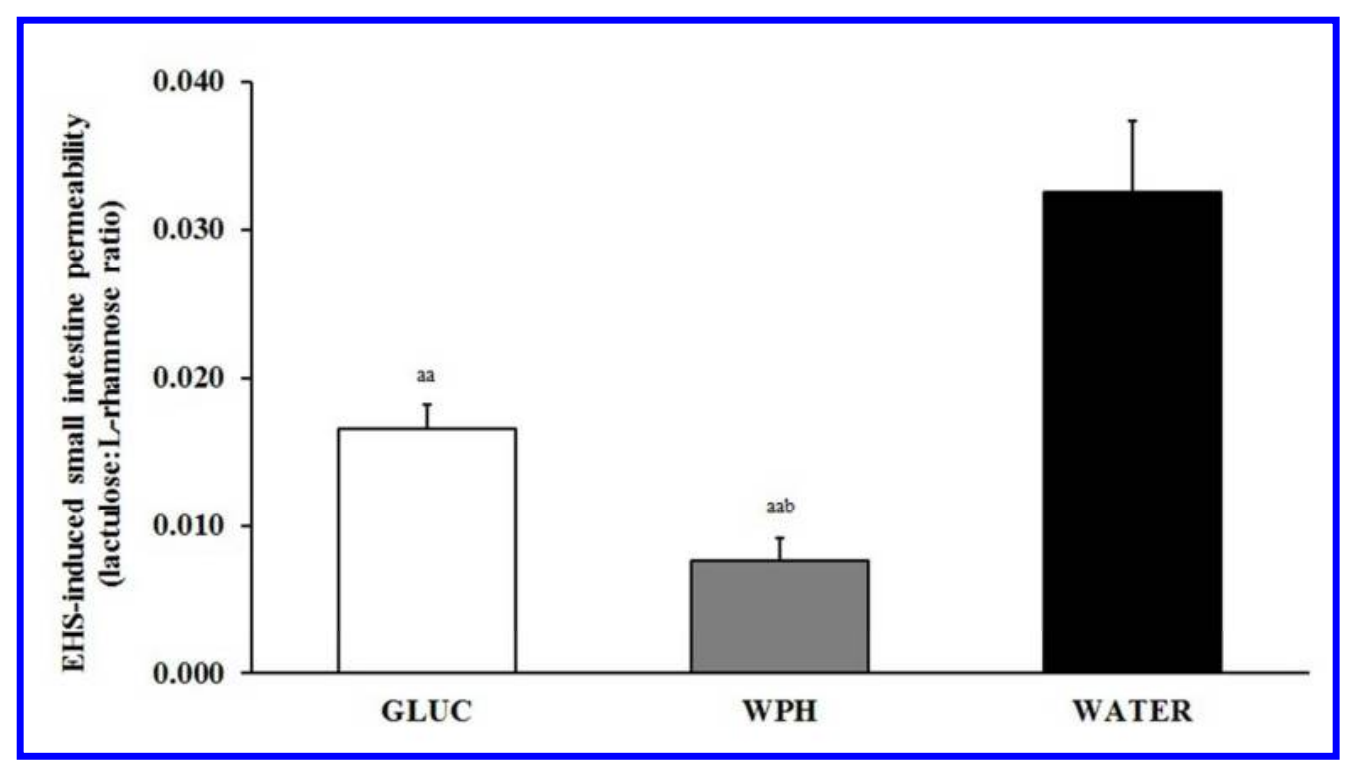

Figure 4: EHS-induced small intestine permeability (lactulose:L-rhamnose ratio) in response to $2 \mathrm{~h}$ running at $60 \%$ VO2max in $35^{\circ} \mathrm{C}$ Tamb on glucose (GLUC), hydrolysed whey protein (WPH) or water (WATER). Mean $\pm \operatorname{SEM}(n=8)$ : aa $p<0.01$ vs. WATER, b $p<0.05$ vs. GLUC.

$73 \times 40 \mathrm{~mm}(300 \times 300 \mathrm{DPI})$ 


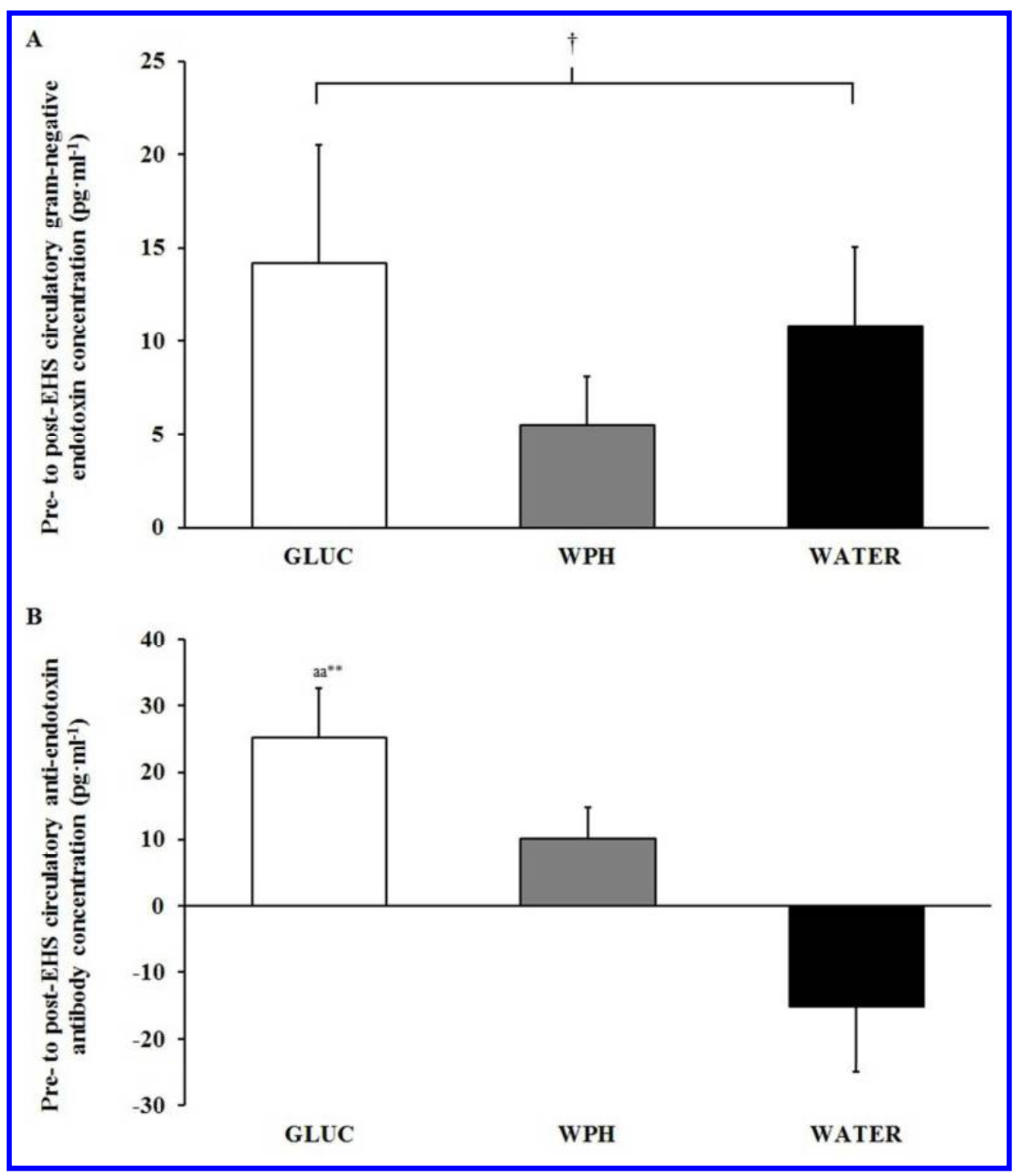

Figure 5: Pre- to post-EHS circulatory gram-negative bacterial endotoxin $(A)$ and anti-endotoxin antibody (B) concentration in response to $2 \mathrm{~h}$ running exercise at $60 \%$ VO2max in $35^{\circ} \mathrm{C}$ Tamb on glucose (GLUC), hydrolysed whey protein (WPH) or water (WATER). Mean and individual responses $(n=9)$ : † main effect of time $\mathrm{p}<0.05$ vs. pre-EHS, $* * \mathrm{p}<0.01$ vs. pre-EHS, aa $\mathrm{p}<0.01$ vs. WATER.

$73 \times 84 \mathrm{~mm}(300 \times 300 \mathrm{DPI})$ 


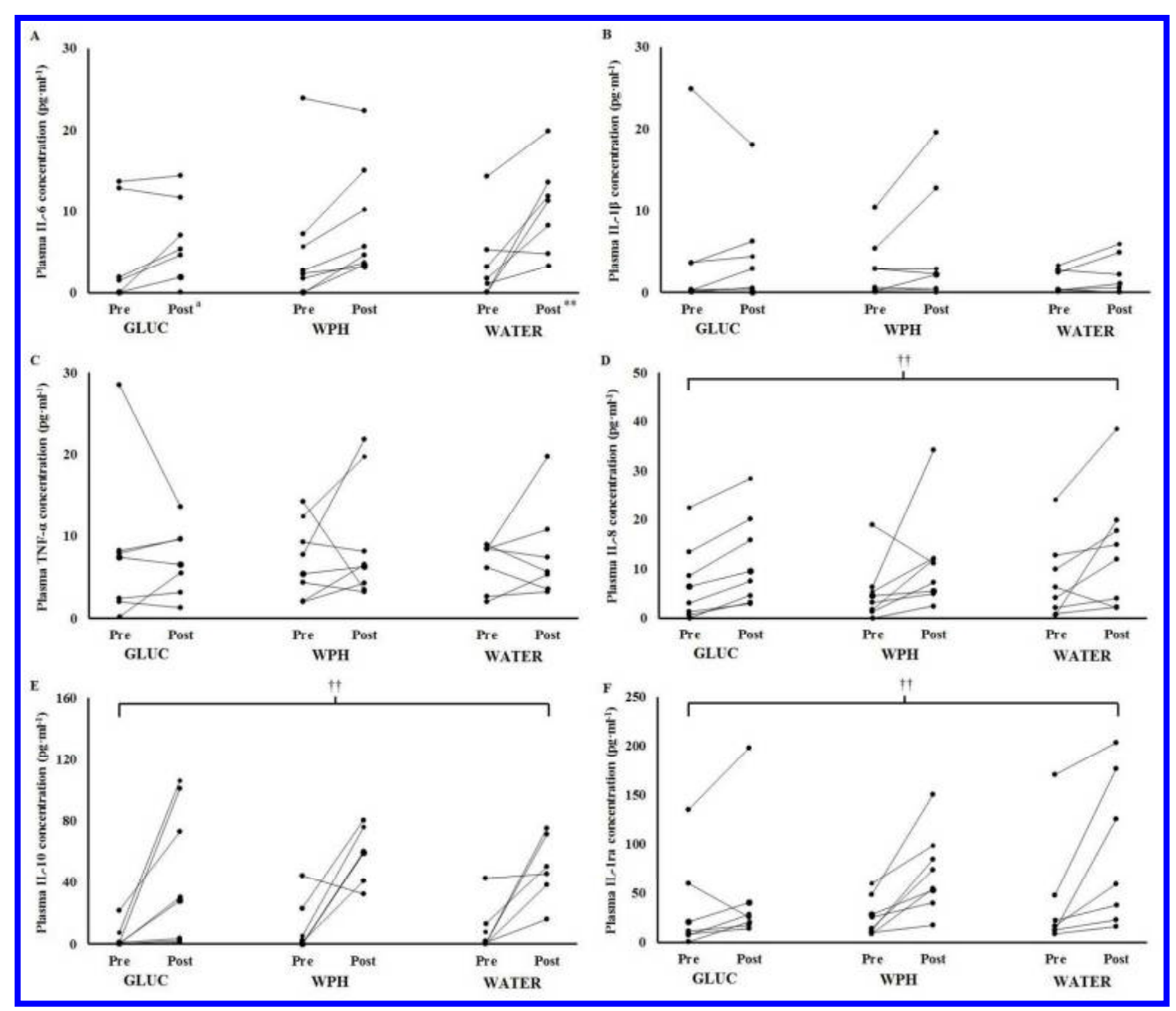

Figure 6: Pre- and post-EHS plasma IL-6 (A), IL-1ß (B), TNF-a (C), IL-8 (D), IL-10 (E), and IL-1ra (F) concentrations in response to $2 \mathrm{~h}$ running exercise at $60 \% \mathrm{VO} 2 \mathrm{max}$ in $35^{\circ} \mathrm{C}$ Tamb on glucose (GLUC), hydrolysed whey protein (WPH) or water (WATER). Individual responses $(n=9)$ : $+\dagger$ main effect of time $p<$ 0.01 pre-EHS vs. post-EHS, $* * p<0.01$ vs. pre-EHS, a $p<0.05$ vs. WATER.

$146 \times 125 \mathrm{~mm}(300 \times 300$ DPI) 